\title{
BMJ Open Effects of culture-sensitive adaptation of patient information material on usefulness in migrants: a multicentre, blinded randomised controlled trial
}

\author{
Lars P Hölzel, ${ }^{1}$ Zivile Ries, ${ }^{1}$ Levente Kriston, ${ }^{2}$ Jörg Dirmaier, ${ }^{2}$ Jördis M Zill, ${ }^{2}$ \\ Christine Rummel-Kluge, ${ }^{3,4}$ Wilhelm Niebling, ${ }^{5}$ Isaac Bermejo, ${ }^{6}$ Martin Härter $^{2}$
}

To cite: Hölzel LP, Ries Z, Kriston L, et al. Effects of culture-sensitive adaptation of patient information material on usefulness in migrants: a multicentre, blinded randomised controlled trial. BMJ Open 2016;6:e012008. doi:10.1136/bmjopen-2016012008

- Prepublication history and additional material is available. To view please visit the journal (http://dx.doi.org/ 10.1136/bmjopen-2016012008).

$\mathrm{IB}$ and $\mathrm{MH}$ are equal contributors.

Received 21 March 2016 Revised 25 September 2016 Accepted 29 September 2016

CrossMark

For numbered affiliations see end of article.

Correspondence to Dr Lars P Hölzel; lars. hoelze!@uniklinik-freiburg.de

\section{ABSTRACT}

Objectives: To evaluate the usefulness of culturesensitive patient information material compared with standard translated material.

Design: Multicentre, double-blind randomised controlled trial.

Setting: 37 primary care practices.

Participants: 435 adult primary care patients with a migration background with unipolar depressive disorder or non-specific chronic low back pain were randomised. Patients who were unable to read in the language of their respective migration background were excluded. Sufficient data were obtained from 203 women and 106 men. The largest group was of Russian origin (202 patients), followed by those of Turkish (52), Polish (30) and Italian (25) origin. Interventions: Intervention group: provision of culture-sensitive adapted material. Control group: provision of standard translated material.

Main outcome measures: Primary outcome: patient-rated usefulness (USE) assessed immediately after patients received the material. Secondary outcomes: patient-rated usefulness after 8 weeks and 6 months, symptoms of depression (PHQ-9), back pain (Back Pain Core Set) and quality of life (WHO-5) assessed at all time points.

Results: Usefulness was found to be significantly higher $(t=1.708$, one-sided $p=0.04)$ in the intervention group (USE-score $=65.08, \mathrm{SE}=1.43$ ), compared with the control group (61.43, $\mathrm{SE}=1.63)$, immediately after patients received the material, in the intention-to-treat analysis, with a mean difference of 3.65 (one-sided $95 \%$ lower confidence limit $=0.13$ ). No significant differences were found for usefulness at follow-up $(p=0.16, p=0.71)$. No significant effect was found for symptom severity in depression $(p=0.95, p=0.66$, $p=0.58)$, back pain $(p=0.40, p=0.45, p=0.32)$ or quality of life ( $p=0.76, p=0.86, p=0.21)$, either immediately after receiving the material, or at follow-up (8 weeks; 6 months). Patients with a lower level of dominant society immersion benefited substantially and significantly more from the intervention than patients with a high level of immersion ( $p=0.005)$.

Conclusion: Cultural adaptation of patient information material provides benefits over high quality

\section{Strengths and limitations of this study}

- High internal and external validity of the study design.

- Blinding of patients and general practitioners (GPs) with regard to study group allocation.

- Blinding of statistician to ensure objectivity.

- Questionnaire-based outcomes.

- High clinical heterogeneity of the sample may have diluted intervention effects.

translations. Clinicians are encouraged to use culturesensitive material in their consultations, particularly with low-acculturated patients.

Trial registration number: German Register for Clinical Trials: DRKS00004241, Universal Trial Number: U1111-1135-8043, Results.

\section{BACKGROUND}

Migration is an increasingly important global issue. A substantial and growing proportion $(\sim 20 \%$ at present) of the German population has a migration background. ${ }^{1}$ Provision of a high quality of care regardless of cultural background is challenging both for physicians and policymakers. ${ }^{2}$ Currently, migrants often receive poorer care than the indigenous population. ${ }^{3-6}$ In Germany, migrants are frequently poorly informed and underuse preventive healthcare services. ${ }^{7}$

Therefore, evidence-based measures to improve care for migrants are urgently needed. However, high-quality studies on healthcare interventions for migrants are lacking. ${ }^{2}$

Patient engagement and empowerment are central issues in current debates on improving healthcare, ${ }^{8}$ especially for chronic illnesses and mental disorders. ${ }^{9}$ A fundamental strategy to promote patient engagement and 
empowerment is the improvement of health literacy. ${ }^{8}$ Written patient information materials (PIMs) are a useful adjunct to professional consultation and expert advice, in order to inform and educate patients and thus increase their engagement and empowerment. ${ }^{8} 10$

Language-appropriate PIMs for migrants are often 'one of the first and most critical' interventions to improve healthcare, as they can help to overcome language barriers. ${ }^{11}$ However, a simple translation may not sufficiently provide for cultural differences. ${ }^{12}$ An additional cultural adaptation may therefore be needed.

There is a growing body of evidence for the positive effects of culturally adapted interventions. Meta-analyses for culturally adapted psychotherapy and health-related training exist. ${ }^{13-15}$ A randomised controlled trial comparing standard and culture-sensitive PIMs for African-American adults found promising results in favour of culture-sensitive PIMs. ${ }^{16}$ However, there is a lack of randomised controlled trials with patients and physicians blinded for group allocation and comparing culture-sensitive PIM with high-quality translations. The aim of the present study was to address this in a multicentre randomised controlled trial.

\section{METHODS}

Design

The effects of culture-sensitive PIMs, compared with standard translated PIMs, were investigated in a patientblinded, physician-blinded and statistician-blinded randomised controlled multicentre trial. Participants were recruited from primary care, as general practitioners (GPs) usually serve as the first point of contact in healthcare. Patients in this setting often need initial information on their health problem and treatment options, which can be provided in PIMs. Academic training practices, practices in cooperating networks and publicly registered GPs in the areas of Freiburg, Hamburg, Oberhausen-Mülheim-Duisburg and Leipzig were invited to participate in the study.

Further information can be found in the published study $\operatorname{protocol}^{17}$ and the study registration at the German Register for Clinical Trials (DRKS00004241).

\section{Inclusion and exclusion criteria}

Adult primary care patients with a Turkish, Polish, Russian or Italian migration background, and with indications of unipolar depressive disorder (International Classification of Diseases (ICD-10): codes F32.xx, F33.xx, F34.1) or non-specific chronic low back pain (ICD-10 codes: M54.5, M54.8, M54.9), based on clinical diagnosis, were eligible for inclusion in our randomised trial. Migration background was defined according to the definition of the Federal Statistical Office of Germany as being of non-German nationality, having a first language other than German, being born in another country or having a parent who was born in a country other than Germany. ${ }^{1} 18$ To be eligible, patients had to identify themselves with their non-German origin. To ensure a high external validity of the study, exclusion criteria were kept to a minimum. Since our intervention was based on written PIMs, and required that patients complete written questionnaires, those who felt unable to read PIMs in the language of their respective migration background were excluded.

\section{Intervention and comparator}

The PIMs for both illnesses were based on German clinical practice guidelines. ${ }^{19} 20$ Information on prevalence, diagnoses and prognosis, treatment options and responsibilities of different healthcare providers was given. To exclude the influence of potentially confounding factors other than culture, we focused on developing highquality materials that were suitable for migrants based on aspects other than culture (eg, comprehensibility, length and reading level). The final brochure consisted of 12 pages, and included figures, pictures and illustrative case examples. For the control group (CG), a highquality translation of the German version of the PIMs was administered, using the forward-backward translation procedure. ${ }^{21}$ Patients in the intervention group (IG) received the culture-sensitive PIMs, which were based on the translated version and included adaptations for the respective migration background. The adaptations were based on the results of four separate focus groups, one for each migration background. ${ }^{17}$ In these focus groups, the cultural appropriateness of the translated materials was discussed. Focus group participants had to have one of the four relevant migration backgrounds and live in Germany. They also had to be able to read and write in German and in the language of the country of their origin. The group discussions were audio recorded, transcribed, analysed using qualitative methods and adapted based on the qualitative results. Cultural adaptations primarily focused on presentation; the core information remained unchanged and patients in both groups received evidence-based information in their native language (see tables 1 and 2). Detailed descriptions of the adaptation process and the focus group results are published in the study protocol ${ }^{17}$ or are being prepared for publication. The PIMs can be found at http://rg-hoelzel. uniklinik-freiburg.de/material.

\section{Administration}

GPs of academic training practices, practices of the cooperating networks and GPs listed in public registers were invited to participate in the study. GPs consecutively assessed patients for eligibility and applied inclusion and exclusion criteria (for details, see ref. 17). Eligible patients were invited to participate by the GP and received information on the study after the consultation $\left(-\mathrm{T}_{1}\right.$, enrolment). Written informed consent was obtained by the GP. To ensure comprehensibility of the information, translated consent forms were used. GPs then handed out a sealed envelope ( $T_{0}$, allocation) 
Table 1 Culture-sensitive adaptations of patient information materials for depression

\begin{tabular}{|c|c|c|c|c|}
\hline Component (standard version) & Italian & Polish & Russian & Turkish \\
\hline $\begin{array}{l}\text { Cover picture (young woman } \\
\text { sitting in front of a laptop, holding } \\
\text { her head and looking sad) }\end{array}$ & $\begin{array}{l}\text { Cover picture changed to an } \\
\text { elderly woman } \\
\text { Background colour changed } \\
\text { from grey to black }\end{array}$ & No changes & $\begin{array}{l}\text { Cover picture changed to a } \\
\text { woman sitting on the floor }\end{array}$ & No changes \\
\hline $\begin{array}{l}\text { Illustrative case examples } \\
\text { (German names, professions: } \\
\text { bricklayer, doctor's receptionist, } \\
\text { teacher, pensioner) }\end{array}$ & $\begin{array}{l}50 \% \text { Italian names } \\
\text { Professions: carpenter, } \\
\text { doctor's receptionist, cleaner, } \\
\text { bank employee }\end{array}$ & $\begin{array}{l}50 \% \text { Polish names } \\
50 \% \text { pictures of people of Polish } \\
\text { appearance }\end{array}$ & No changes & $\begin{array}{l}50 \% \text { Turkish names } \\
50 \% \text { pictures of people of } \\
\text { Turkish appearance }\end{array}$ \\
\hline $\begin{array}{l}\text { Social themes of different topics of } \\
\text { the PIM (not in the focus) }\end{array}$ & $\begin{array}{l}\text { Social themes 'relations with } \\
\text { friends and family' were } \\
\text { incorporated into several } \\
\text { topics } \\
\text { 'Material conflicts on } \\
\text { returning to Italy or staying in } \\
\text { Germany' was used as an } \\
\text { example for a social risk } \\
\text { factor for depression }\end{array}$ & No changes & No changes & $\begin{array}{l}\text { Social themes 'relations with } \\
\text { friends, family and neighbours' } \\
\text { were incorporated into several } \\
\text { topics }\end{array}$ \\
\hline $\begin{array}{l}\text { Biological aspects (explanation of } \\
\text { the biopsychosocial model of } \\
\text { depression, no additional } \\
\text { explanation on the rationale for } \\
\text { antidepressant use) }\end{array}$ & $\begin{array}{l}\text { Additional biological } \\
\text { mechanisms/rationale for } \\
\text { antidepressant use: } \\
\text { explained in more depth }\end{array}$ & No changes & No changes & No changes \\
\hline $\begin{array}{l}\text { Specific metaphors/idioms ('grey' } \\
\text { for depression, to feel 'very small') }\end{array}$ & 'Black' for depression & No changes & No changes & 'Life has lost its taste' \\
\hline $\begin{array}{l}\text { Stigma (only information on } \\
\text { prevalence of depression in } \\
\text { general) }\end{array}$ & No changes & $\begin{array}{l}\text { Additional antistigma statement } \\
\text { (depression can affect everyone, } \\
\text { is not a personal failure, is a } \\
\text { medical condition, can be treated } \\
\text { effectively, is curable) }\end{array}$ & $\begin{array}{l}\text { Additional antistigma statement } \\
\text { (depression can affect everyone, } \\
\text { is a medical condition, is an } \\
\text { indication to seek professional } \\
\text { help, is curable) }\end{array}$ & $\begin{array}{l}\text { Additional antistigma } \\
\text { statement (depression can } \\
\text { affect everyone, is a medical } \\
\text { condition, can be treated } \\
\text { effectively, is curable) }\end{array}$ \\
\hline $\begin{array}{l}\text { Health insurance (information on } \\
\text { costs for psychotherapeutic } \\
\text { methods that are covered) }\end{array}$ & No changes & $\begin{array}{l}\text { Information on costs for } \\
\text { therapeutic methods that are } \\
\text { covered } \\
\text { Additional information on costs for } \\
\text { single therapy sessions that are } \\
\text { covered }\end{array}$ & No changes & No changes \\
\hline $\begin{array}{l}\text { Medication (information on } \\
\text { antidepressants: effects, side } \\
\text { effects, no risk of dependence, no } \\
\text { effects on personality) }\end{array}$ & No changes & $\begin{array}{l}\text { Differences between } \\
\text { antidepressants and other } \\
\text { psychotropic drugs }\end{array}$ & No changes & No changes \\
\hline
\end{tabular}




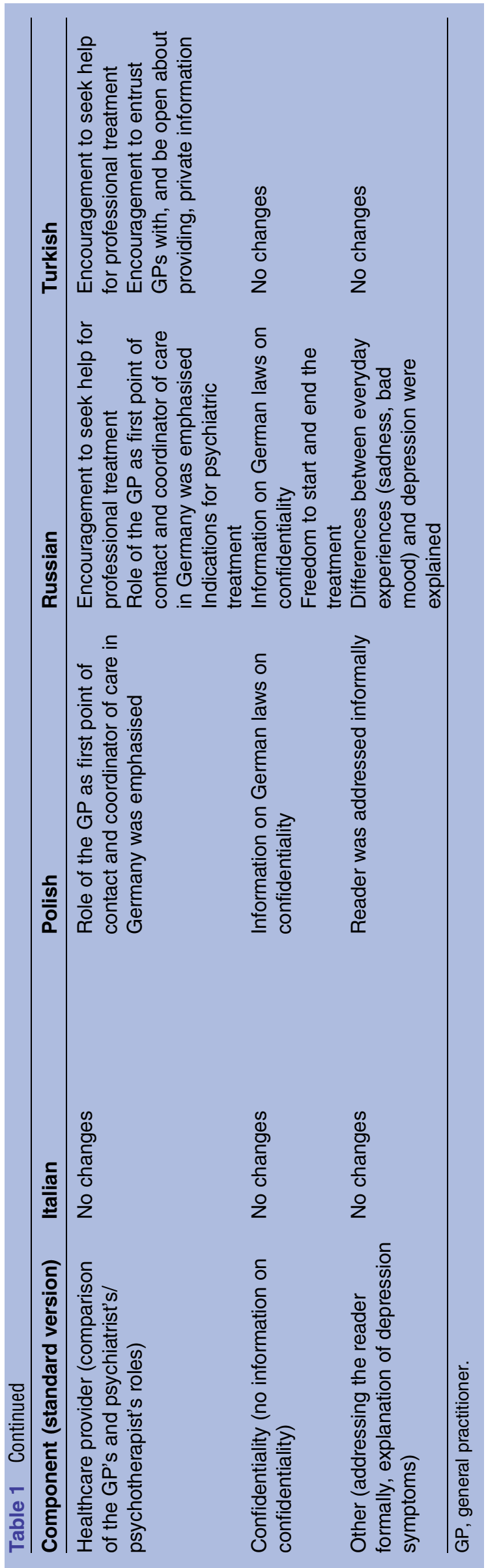

containing the PIM and a questionnaire. By using sealed envelopes, it was ensured that both GPs and patients were blind to the group allocation. The content of the envelopes (standard translated vs culturally adapted PIMs) was centrally randomised by a computer-based algorithm with a 1:1 allocation ratio, and stratified by physician, illness and migration background with varying block sizes. The random allocation sequence was generated by the trial statistician and prepared by the research team (whose members were not directly involved in patient recruitment). Concomitant care was not restricted in any way. After the consultation, patients were asked to read the PIMs and fill in the questionnaire containing all $\mathrm{T}_{1}$-measures $\left(\mathrm{T}_{1}\right.$, after consultation) and return it by post (detailed information can be found in the published study protocol). ${ }^{17}$ At 8 weeks $\left(\mathrm{T}_{2}\right)$ and 6 months $\left(\mathrm{T}_{3}\right)$ after the consultation, patients were contacted by post and asked to fill in follow-up questionnaires. Patients were reminded by the leading study centre, by telephone after 2 weeks and by post after 3 weeks, if they had still not sent back the questionnaire. To ensure a sufficient response rate at each time point, patients received an unconditional reimbursement of $€ 5$ for filling in each questionnaire. ${ }^{22}$ GPs received an allowance of $€ 40$, and the receptionist $€ 5$, per patient recruited.

\section{Measures}

Age (years), sex, duration of residence in Germany (years), education (number of years) and level of acculturation (Stephenson Multigroup Acculturation Scale, SMAS) ${ }^{23}$ were assessed at $\mathrm{T}_{1}$. The SMAS has two scales: 'ethnic society immersion' (describing the level of identification with the native culture) and 'dominant society immersion' (describing the level of acculturation in the dominant society of habitation).$^{23}$

According to current theories for the evaluation of the effectiveness of PIMs, and consistent with the concept of patient empowerment, the patient's judgement of usefulness is the final outcome in the process of reading, understanding and responding to PIMs. ${ }^{24}$ An instrument to assess this judgement is the Usefulness Scale for Patient Information Material (USE). ${ }^{25}$ Therefore, we chose this scale to assess the primary outcome, usefulness, after patients had consulted and read the material $\left(T_{1}\right)$. Usefulness is measured on a global scale over three subscales which assess cognitive, emotional and behavioural subdimensions. The global score ranges from 0 to 90 , and each subscale score ranges from 0 to 30 . High scores indicate high usefulness of the PIMs. The instrument showed excellent psychometric properties. ${ }^{25}$ Our primary hypothesis was that culturally adapted PIMs are perceived to be more useful than the standard translated materials.

Secondary outcomes were usefulness of PIMs (measured on the USE) assessed after 8 weeks $\left(T_{2}\right)$ and 6 months $\left(\mathrm{T}_{3}\right)$; subdimensions of usefulness (also measured on the USE); symptoms of depression or back 
Table 2 Culture-sensitive adaptations of patient information materials for chronic low back pain

\begin{tabular}{|c|c|c|c|c|}
\hline $\begin{array}{l}\text { Component (standard } \\
\text { version) }\end{array}$ & Italian & Polish & Russian & Turkish \\
\hline $\begin{array}{l}\text { Illustrative case examples } \\
\text { (German names; } \\
\text { professions: seller, bank } \\
\text { employee, professor, } \\
\text { housewife) }\end{array}$ & $\begin{array}{l}50 \% \text { Italian names } \\
\text { Professions: retired } \\
\text { tram conductor, } \\
\text { confectioner, sales } \\
\text { person, teacher } \\
\text { Inclusion of } \\
\text { pensioner } \\
\text { Housewife was } \\
\text { changed to teacher }\end{array}$ & $\begin{array}{l}50 \% \text { Polish names } \\
50 \% \text { pictures of } \\
\text { people of Polish } \\
\text { appearance } \\
\text { Professions: } \\
\text { electrician, student, } \\
\text { tax consultant, } \\
\text { housewife }\end{array}$ & $\begin{array}{l}\text { All illustrative case } \\
\text { examples were } \\
\text { deleted }\end{array}$ & $\begin{array}{l}50 \% \text { Turkish names } \\
50 \% \text { pictures of people } \\
\text { of Turkish appearance }\end{array}$ \\
\hline $\begin{array}{l}\text { Social themes of different } \\
\text { topics of the PIM (not in } \\
\text { the focus) }\end{array}$ & $\begin{array}{l}\text { Social themes } \\
\text { 'relations with friends } \\
\text { and family' were } \\
\text { incorporated into } \\
\text { several topics }\end{array}$ & No changes & No changes & $\begin{array}{l}\text { Information incorporated } \\
\text { outlining the benefits of } \\
\text { social support for } \\
\text { treatment of chronic low } \\
\text { back pain, especially in } \\
\text { 'becoming more active' }\end{array}$ \\
\hline $\begin{array}{l}\text { Healthcare provider } \\
\text { (multidisciplinary } \\
\text { approach, GP as central } \\
\text { coordinator of care) }\end{array}$ & $\begin{array}{l}\text { Role of the GP as } \\
\text { first point of contact } \\
\text { and coordinator of } \\
\text { care was highlighted }\end{array}$ & $\begin{array}{l}\text { Responsibility of the } \\
\text { GP for diagnosis } \\
\text { and treatment was } \\
\text { highlighted }\end{array}$ & $\begin{array}{l}\text { Responsibility of the } \\
\text { GP for diagnosis and } \\
\text { treatment was } \\
\text { highlighted }\end{array}$ & No changes \\
\hline $\begin{array}{l}\text { Diagnosis (consultation } \\
\text { and physical examination } \\
\text { as standard, further tests if } \\
\text { another illness suspected) }\end{array}$ & No changes & No changes & $\begin{array}{l}\text { It was highlighted that } \\
\text { imaging procedures } \\
\text { are not needed in } \\
\text { routine procedure }\end{array}$ & No changes \\
\hline $\begin{array}{l}\text { Physical activities (fitness } \\
\text { studio, swimming) }\end{array}$ & $\begin{array}{l}\text { Changed from } \\
\text { fitness studio and } \\
\text { swimming to going } \\
\text { for a walk and a bike } \\
\text { ride }\end{array}$ & No changes & $\begin{array}{l}\text { In-depth explanation } \\
\text { on why rest is harmful } \\
\text { and why physical } \\
\text { activities are so } \\
\text { important }\end{array}$ & $\begin{array}{l}\text { Changed from fitness } \\
\text { studio and swimming to } \\
\text { going for a walk and a } \\
\text { bike ride } \\
\text { Differences between } \\
\text { homework, manual work } \\
\text { and physical activities } \\
\text { were highlighted }\end{array}$ \\
\hline $\begin{array}{l}\text { Other (Anglicisms } \\
\text { common to German } \\
\text { everyday language were } \\
\text { used) }\end{array}$ & $\begin{array}{l}\text { All Anglicisms were } \\
\text { omitted }\end{array}$ & No changes & No changes & No changes \\
\hline
\end{tabular}

pain assessed by the Patient Health Questionnaire (PHQ-9) and Back Pain Core Set, respectively; ${ }^{26}{ }^{27}$ and quality of life, assessed by the five-item WHO Well-Being Index $(\mathrm{WHO}-5)^{28}$ at all time points $\left(\mathrm{T}_{1}, \mathrm{~T}_{2}, \mathrm{~T}_{3}\right)$.

\section{Statistical analyses}

We compared standard PIMs (the control group) with customised PIMs (as one group) in the main analyses. The common characteristics of the study participants were the migration background and suffering from a chronic disease. Although there was diversity in these variables (four different cultural backgrounds and two different illnesses), we assumed that the main effective component of the intervention (adaptation of information) functioned in a comparable way across all groups. Thus, we considered the groups to be functionally equivalent for the purpose of this study. However, since dealing with clinical heterogeneity is a frequently controversial issue, ${ }^{29}$ we performed a series of sensitivity analyses to test whether migration background, illness or both moderate the intervention effect.

The primary outcome was analysed by a statistician (blinded to group allocation) using a t-test to test the directed hypothesis that the culturally adapted PIM is superior to the standard PIM, as specified in the study protocol. ${ }^{17}$ According to the intention-to-treat principle, all randomised participants were included in this analysis. The required sample size for the primary outcome analysis was determined to be 280 patients (140 per group, with an expected Cohen's d of 0.3, a one-sided type I error of 0.05 and a power of $80 \%$ ) with sufficiently complete data (ie, missing data $\leq 30 \%) .{ }^{17}$ At the scale level, missing data were handled by applying expectationmaximisation imputation. For the intention-to-treat analysis, missing data at the case level were handled using multiple imputation. We used an iterative Markov chain Monte Carlo (MCMC) method (fully conditional specification) with 20 imputations. ${ }^{30}$ Predictor variables 
for imputing missing values were study region, illness and migration background, as these were the only available data from patients not responding at $\mathrm{T}_{1}$. All secondary analyses were of an explorative nature and performed by fitting a repeated measures random-intercept mixed model with the three measurement time points clustered within participants (scaled identity covariance structure for repeated measures) ${ }^{31}$ and group allocation, time point and the group $\times$ time point interaction as explanatory variables. In additional analyses, moderation effects of study region, illness, migration background, symptom severity and level of acculturation ${ }^{23}$ were tested by amending the model with the respective variables and their interaction with the group variable. All analyses were performed using IBM SPSS Statistics V.21.0 (IBM Corporation, Armonk, New York, USA) and conducted in accordance with the study registration and study protocol. ${ }^{17}$

\section{Results}

From June 2013 to August 2014, 37 primary care practices invited 503 patients to participate in the study. Recruitment ended after the targeted statistical power was reached. Two patients did not identify themselves with their migration background and therefore did not meet the inclusion criteria. Two patients were excluded because written consent was not obtained. Sixty-four patients refused to participate for the following reasons: not interested in the study topic (34 patients), did not want to use written material (6 patients), were suspicious of scientific studies (4 patients), had problems with reading (3 patients), felt too ill to participate (2 patients), were unable to read the language of the PIMs (1 patient) or had other or undisclosed reasons (14 patients). We randomised 435 participants, of whom 317 responded at $\mathrm{T}_{1}(72.9 \%)$ and $309(71.0 \%)$ were included in the analyses (missing data $\leq 30 \%$; see figure 1). Data from 288 patients (64.7\%, $C G=136$, $\mathrm{IG}=152)$ at $\mathrm{T}_{2}$ and 261 patients $(58.7 \%, \mathrm{CG}=125$, $\mathrm{IG}=136)$ at $\mathrm{T}_{3}$ were analysed.

A dropout analysis using binary logistic regression indicated that group allocation, study region, illness, migration background and the two-way interaction terms between group allocation and all other variables were not significantly associated with dropping out between randomisation and $\mathrm{T}_{1}$ (Nagelkerke's $\mathrm{R}^{2}=0.07, \chi^{2}{ }^{15}=21.4$, $\mathrm{p}=0.13$ ). Approximately $1.7 \%$ of the total data points were missing at the item level and imputed by expectation-maximisation. For the primary analysis, data for 126 of 435 randomised patients (29.0\% missing) were imputed by multiple imputation.

\section{Sample characteristics}

Demographic and clinical characteristics are reported in table 3. More women than men participated in the study. Age distribution of participants was $15.7 \%$ between 18 and 40 years, $52 \%$ between 41 and 60 years and $32.4 \%$ older than 60 . On average, participants had $\sim 10$ years of education. The average duration of residency in Germany was 20 years, with $4.5 \%$ living in Germany for up to 5 years, $37.8 \%$ between 6 and 15 years, $36.4 \%$ between 16 and 25 years and $21.3 \%$ more than 26 years. More patients with chronic low back pain than patients with depression were recruited. The majority of patients were in the group with a Russian migration background, with the Turkish group as the second largest, followed by the Polish and Italian groups. The intervention and control groups were well balanced with respect to sample characteristics of patients.

\section{Primary outcome}

Both groups reported high scores for the subjective usefulness of the PIMs after the consultation $\left(\mathrm{T}_{1}\right)$. The IG group (227 patients) had a mean score of 65.08 ( $\mathrm{SE}=1.43$ ) and the $\mathrm{CG}$ group (208 patients) had a mean score of $61.43(\mathrm{SE}=1.63)$. Accordingly, the average rating in the IG group was $\sim 4$ points higher than in the CG group (mean difference 3.65; one-sided $95 \%$ lower confidence limit $=0.13)$. This difference reached statistical significance (one-sided $\mathrm{t}=1.708, \mathrm{p}=0.04$ ). The results correspond to a standardised mean difference (Cohen's d) of 0.18 .

In a sensitivity analysis using a mixed models approach including all available data, we confirmed the results for the primary outcome $(p=0.03)$ with a similar mean difference $(4.41$; one-sided $95 \%$ lower confidence limit=0.47).

\section{Secondary outcomes}

Regarding the usefulness of PIMs, the difference between the two groups decreased over time (see table 4). No statistically significant differences were found for total score after 8 weeks $\left(T_{2}\right)$ or 6 months $\left(T_{3}\right)$. The emotional subscale showed a statistically significant difference at $\mathrm{T}_{1} \quad(\mathrm{p}=0.020 ;$ mean difference $=2.15 ; 95 \%$ CI 0.34 to 3.96$)$, a tendency at $\mathrm{T}_{2}$ ( $p=0.07$; mean difference $=1.73 ; 95 \%$ CI -0.14 to 3.60 ) and no difference at $\mathrm{T}_{3}(\mathrm{p}=0.54$; mean difference $=0.61$; $95 \%$ CI -1.33 to 2.55 ). For the behavioural subscale, scores tended to be higher in the IG at $\mathrm{T}_{1}$. We found no significant statistical effect for the cognitive subscale, symptom severity of illness (depression or back pain) or quality of life.

\section{Effect moderators}

Study region, illness and symptom severity were not found to be associated with intervention effect regarding the primary outcome $(p>0.10$; see online supplementary materials for details). However, the difference between the IG and CG was 11.33 points smaller $(95 \%$ CI -24.33 to $1.68 ; \mathrm{p}=0.09$ ) in patients with a Polish migration background than in those with a Russian background. Furthermore, the superiority of the adapted PIM over the standard PIM was substantially larger in patients with a low level of dominant society immersion 


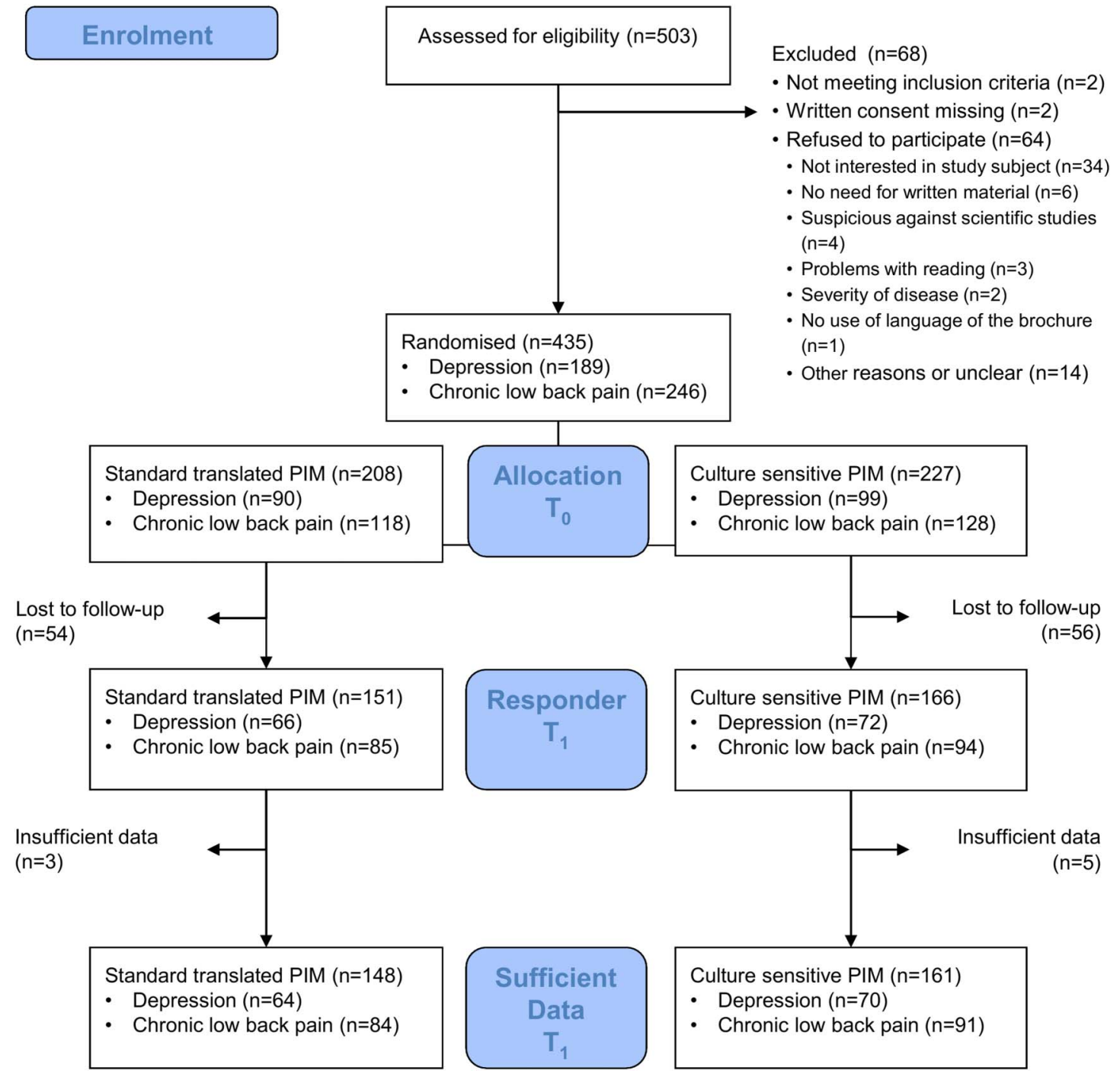

Figure 1 Patient flow diagram.

(acculturation) than in high-acculturated patients. The intervention versus control difference in usefulness was 14.69 points, with one step decrease in acculturation on a four point scale (95\% CI 4.46 to $24.91 ; \mathrm{p}=0.005$ ). Acculturation was also shown to be responsible for the aforementioned difference in effectiveness between Polish and Russian patients (the Polish patients were better acculturated than the Russian ones), turning the effect of migration background non-significant $(p>0.10)$ when added to the model (see online supplementary materials for details).

\section{DISCUSSION}

In this trial, we investigated the effects of cultural adaptation of high-quality translations of PIMs. While both versions were rated to be of high subjective usefulness, the adapted material was judged to be significantly more useful than the translated version after reading the PIM, which was handed out by the GP after the consultation. However, this difference decreased over time and was not statistically significant after 8 weeks or 6 months. The initial difference was mainly driven by differences on the emotional subscale. Further effects on clinical outcomes or quality of life were not found.

A central limitation of our study is that the USE had been developed and validated in German. The translations used in this study had been conducted using the forward-backward method and had been pilot tested by people with migration backgrounds using the think-aloud method. However, an investigation of the psychometric properties of the translated version is still lacking. Another limitation is that all outcomes were questionnaire-based and therefore subjective. However, given that GPs and patients were blinded with regard to study group, an expectation bias seems unlikely. Another limitation is the clinical heterogeneity of the sample. We decided to include patients from various migrant groups, with illness at various stages and with no restrictions relating to duration of residency in Germany. These differences may have diluted the intervention effects. Nevertheless, this heterogeneity improved the 
Table 3 Sample characteristics

\begin{tabular}{|c|c|c|c|}
\hline & Intervention group $(n=161)$ & Control group $(n=148)$ & Total sample $(n=309)$ \\
\hline \multicolumn{4}{|l|}{ Demographic characteristics } \\
\hline \multicolumn{4}{|l|}{ Age; years } \\
\hline Mean (SD) & $54.5(14.4)$ & $55.4(11.7)$ & $54.94(13.1)$ \\
\hline \multicolumn{4}{|l|}{ Sex; n (\%) } \\
\hline Female & $110(68.3)$ & $93(62.8)$ & $203(65.7)$ \\
\hline \multicolumn{4}{|l|}{ Education; years. } \\
\hline Mean (SD) & $10.0(2.6)$ & $9.6(2.2)$ & $9.7(2.4)$ \\
\hline \multicolumn{4}{|c|}{ Duration of residency in Germany; years } \\
\hline Mean (SD) & $19.9(10.7)$ & $19.6(10.6)$ & $19.8(11.5)$ \\
\hline \multicolumn{4}{|l|}{ Illness; n (\%) } \\
\hline Depression & $70(43.5)$ & $64(43.2)$ & $134(43.4)$ \\
\hline Chronic low back pain & $91(56.5)$ & $84(56.8)$ & $175(56.6)$ \\
\hline \multicolumn{4}{|c|}{ Migration background; $n(\%)$} \\
\hline Russian & $104(64.6)$ & $98(66.2)$ & $202(65.4)$ \\
\hline Turkish & $26(16.1)$ & $26(17.6)$ & $52(16.8)$ \\
\hline Polish & $17(10.6)$ & $13(8.8)$ & $30(9.7)$ \\
\hline Italian & 14 (8.7) & $11(7.4)$ & $25(8.1)$ \\
\hline
\end{tabular}

recruitment potential and is likely to have increased the external validity of the results. Similar limitations exist regarding the study intervention. Given the fact that we developed eight different versions of culture-adapted PIMs, which included versions for depression and chronic low back pain for four different migration backgrounds, the effects for some of the secondary outcomes may have been diluted. On the other hand, we used the same procedure to develop all culturally adapted materials. ${ }^{17}$ The level of comparison is therefore the effect of culturally adapted materials in patients with migration backgrounds living in Germany and suffering from a potentially chronic illness. Moderator analyses supported the assumption of functional equivalence of the intervention across migration backgrounds and illnesses, but also suggested that the superiority in usefulness of the adapted over the standard materials is likely to be substantially larger in patients with a low rather than a high level of acculturation.

The key strength of this study is the high internal and external validity. By applying a central randomisation procedure, using a computer-based algorithm with varying block sizes and by providing patients with the PIMs and questionnaire in sealed envelopes, allocation bias seems unlikely. The use of sealed envelopes, to blind patients and GPs with regard to study group allocation, was carried out to prevent performance bias. The statistician was also blind to patient group allocation when primary analysis was performed, to ensure objectivity. These measures ensured a high internal validity.

The involvement of a large number of primary care practices in four different regions of Germany, the evaluation of four migrant groups and two different illnesses, as well as the broad inclusion criteria, ensured a high external validity of the results. The dropout rate was lower than expected and a systematic dropout is unlikely. In consideration of the low rate of refusal to participate in the study and the low dropout rate, we conclude that acceptance of our intervention was high in our sample. However, we cannot conclusively determine the representativeness of our sample. The sample seems to be older and contain a higher proportion of women than the general population with a migration background. ${ }^{1}$ Since patients with chronic low back pain and depression are usually older and predominantly female, these differences may be caused by the illnesses investigated and the recruitment setting. The mean duration of residency ( 20 years $)$ is not unusual for people with a migration background in Germany.

Our study adds new insight to the importance of cultural sensitivity in healthcare provision. To the best of our knowledge, this is the first trial to examine the effects of cultural adaptation of PIMs beyond highquality translation. Although there is a growing literature on the effects of culture-sensitive interventions in general, $^{32} 33$ studies have not usually been able to prevent performance bias (by blinding patients and GPs with regard to study group allocation). Moreover, language and other cultural aspects often confound interpretation. These two limitations did not apply to this trial.

Differences in usefulness of the PIMs found right after the consultation $\left(T_{1}\right)$ were largely consistent over different study regions, illness type, migration backgrounds and level of symptom severity, although the moderation analyses are likely to have been underpowered to a certain degree. Nevertheless, we were able to demonstrate a large and stable moderating effect of acculturation with potentially far-reaching implications. Even if the identified effect is on average rather small (Cohen's 
Table 4 Secondary outcomes

\begin{tabular}{|c|c|c|c|c|c|}
\hline \multirow{2}{*}{$\begin{array}{l}\text { Outcome } \\
\text { Time point }\end{array}$} & \multicolumn{2}{|c|}{ Estimated marginal means (SE) } & \multicolumn{3}{|c|}{ Estimated mean difference } \\
\hline & CS-PIM & ST-PIM & $\bar{B}$ & $\mathrm{Cl}^{*}$ & p Value \\
\hline \multicolumn{6}{|c|}{ Usefulness of information (USE) } \\
\hline $\mathrm{T}_{1}$ & $66.39(1.67)$ & $61.98(1.73)$ & 4.41 & 0.47 to $\infty$ & 0.03 \\
\hline $\mathrm{T}_{2}$ & $63.89(1.70)$ & $60.43(1.79)$ & 3.46 & -1.39 to 8.31 & 0.16 \\
\hline $\mathrm{T}_{3}$ & $61.58(1.78)$ & $60.63(1.85)$ & 0.94 & -4.08 to 5.97 & 0.71 \\
\hline \multicolumn{6}{|c|}{ Usefulness-cognitive (USE) } \\
\hline $\mathrm{T}_{1}$ & $23.22(0.59)$ & $22.44(0.62)$ & 0.78 & -0.90 to 2.46 & 0.36 \\
\hline $\mathrm{T}_{2}$ & $21.83(0.61)$ & $20.95(0.64)$ & 0.88 & -0.85 to 2.61 & 0.32 \\
\hline $\mathrm{T}_{3}$ & $21.26(0.63)$ & $21.30(0.66)$ & -0.04 & -1.83 to 1.76 & 0.97 \\
\hline \multicolumn{6}{|c|}{ Usefulness-emotional (USE) } \\
\hline $\mathrm{T}_{1}$ & $20.70(0.64)$ & $18.55(0.67)$ & 2.15 & 0.34 to 3.96 & 0.02 \\
\hline $\mathrm{T}_{2}$ & $20.60(0.66)$ & $18.86(0.69)$ & 1.73 & -0.14 to 3.60 & 0.07 \\
\hline $\mathrm{T}_{3}$ & $19.73(0.69)$ & $19.12(0.71)$ & 0.61 & -1.33 to 2.55 & 0.54 \\
\hline \multicolumn{6}{|c|}{ Usefulness_behavioural (USE) } \\
\hline $\mathrm{T}_{1}$ & $22.46(0.59)$ & $21.02(0.61)$ & 1.44 & -0.23 to 3.11 & 0.09 \\
\hline $\mathrm{T}_{2}$ & $21.55(0.61)$ & $20.64(0.64)$ & 0.92 & -0.81 to 2.64 & 0.30 \\
\hline $\mathrm{T}_{3}$ & $20.65(0.63)$ & $20.24(0.66)$ & 0.42 & 1.37 to 2.20 & 0.65 \\
\hline \multicolumn{6}{|c|}{ Symptoms—depression (PHQ-9) } \\
\hline $\mathrm{T}_{1}$ & $13.40(0.82)$ & $13.48(0.85)$ & -0.08 & -2.40 to 2.24 & 0.95 \\
\hline $\mathrm{T}_{2}$ & $12.51(0.85)$ & $11.97(0.86)$ & 0.54 & -1.85 to 2.93 & 0.66 \\
\hline $\mathrm{T}_{3}$ & $11.53(0.88)$ & $12.23(0.88)$ & -0.69 & -3.14 to 1.75 & 0.58 \\
\hline \multicolumn{6}{|c|}{ Symptoms-back pain (core set) } \\
\hline $\mathrm{T}_{1}$ & $4.32(0.13)$ & $4.16(0.13)$ & 0.15 & -0.20 to 0.51 & 0.40 \\
\hline $\mathrm{T}_{2}$ & $4.18(0.13)$ & $4.04(0.14)$ & 0.14 & -0.22 to 0.51 & 0.45 \\
\hline $\mathrm{T}_{3}$ & $4.28(0.13)$ & $4.09(0.14)$ & 0.19 & -0.19 to 0.58 & 0.32 \\
\hline \multicolumn{6}{|c|}{ Quality of life (WHO-5) } \\
\hline $\mathrm{T}_{1}$ & $10.32(0.43)$ & $10.13(0.45)$ & 0.19 & -1.03 to 1.41 & 0.76 \\
\hline $\mathrm{T}_{2}$ & $10.93(0.44)$ & $11.04(0.46)$ & -0.11 & -1.36 to 1.13 & 0.86 \\
\hline $\mathrm{T}_{3}$ & $10.92(0.45)$ & $11.74(0.47)$ & -0.82 & -2.10 to 0.46 & 0.21 \\
\hline
\end{tabular}

${ }^{*}$ Primary outcome: one-sided $95 \% \mathrm{Cl}$, all other outcomes two-sided $95 \% \mathrm{Cl}$.

†Primary outcome: one-sided test, all other outcomes two-sided tests.

$\mathrm{B}$, mean difference; CS-PIM, culture-sensitive patient information material; PHQ-9, 9-item version of the Patient Health Questionnaire; SMAS, Stephenson Multigroup Acculturation Scale; ST-PIM, standard translated patient information material; $T_{1}$, time point 1 (after consultation); $T_{2}$, time point 2 (after 8 weeks); $T_{3}$, time point 3 (after 6 months); USE, Usefulness Scale for Patient Information Material; WHO-5, WHO-Five Well-Being Index.

$\mathrm{d}$ of 0.18 ), the pragmatic nature of the trial and high heterogeneity of the sample and interventions should be taken into account. Under these conditions, an effect has to be quite robust to cause a detectable difference. Moreover, the comparator (ie, the high-quality translation) should be considered an active control, which may additionally limit the size of the effect detected. In addition, the migrant groups in our study had a long history of migration and cultural exchange. Indeed, most of the patients in our sample had been living in Germany for nearly two decades, which may also have limited the size of the effects observed. The superiority of culturally adapting patient information materials is very likely to be considerably larger in patients with a lower level of acculturation, as suggested by our moderator analyses. Differences in usefulness of the PIMs diminished over time $\left(\mathrm{T}_{2}, \mathrm{~T}_{3}\right)$, which is probably caused by a decrease in intervention effect over time. We did not detect any effect on symptom severity or quality of life. Written PIMs are a useful adjunct to physician consultation and advice, and translation of PIMs is often the first step towards achieving culture-sensitive healthcare. ${ }^{11}$ Our study has important practical implications, as we found reliable evidence that cultural adaptation of PIMs, compared with only high-quality translation, has additional benefits. The cost of adaptation, per PIM, was about $€ 7500$ in our study. Since PIMs can easily be reprinted and distributed, the costs of adaptation are marginal when produced in high print runs. Given the high potential to reach large numbers of patients at low cost, even a small effect may be clinically significant. Cultural adaptation should therefore be considered as a possible option to improve quality when developing PIMs for migrants, and clinicians should be encouraged to use them in their consultations, especially for migrants with low levels of acculturation.

Since we did not standardise the oral consultation, it seems highly likely that the effects of this face-to-face interaction masked the effect of the cultural adaptation. To detect effects of symptom severity or quality of life, a more standardised setting would probably be required. The provision of culturally adapted materials seems a 
promising way of improving PIMs for people with a migration background, particularly in the group of recent immigrants with low levels of acculturation.

\section{Author affiliations}

${ }^{1}$ Department of Psychiatry and Psychotherapy, Medical Center-University of Freiburg, Freiburg, Germany

${ }^{2}$ Department of Medical Psychology, University Medical Center HamburgEppendorf, Hamburg, Germany

${ }^{3}$ Department of Psychiatry and Psychotherapy, University of Leipzig, Leipzig, Germany

${ }^{4}$ German Depression Foundation, Depression Research Center, Leipzig,

Germany

${ }^{5}$ Department of General Practice, Medical Center-University of Freiburg, Freiburg, Germany

${ }^{6}$ Staff Unit Board of Directors, Medical Center-University of Freiburg, Freiburg, Germany

Acknowledgements The authors thank the physician network Qualitätsnetz Oberhausener Ärzte e.V. (Quali-Net 0), namely Angela Brunöhler, Hans Kokorsch and Dr Peter Ramme, for their support in the recruitment process. Professor Caterina Lombardo, La Sapienza University of Rome, Italy; Professor Kaan Kora, Marmara University Medical School, Istanbul, Turkey; Professor Alexander Erichev, Medical Academy of Postgraduate Study Leading Researcher of the St. Petersburg Psychoneurological Research Institute, St. Petersburg, Russia; and Mgr. Marta Kollataj, Collegium Medicum of Jagiellonian University, University Hospital, Kraków, Poland supported us with their invaluable advice regarding cultural differences. The authors thank Julia Albicker for her help in the recruitment process and the data acquisition.

Contributors LPH, ZR, LK, JD, JMZ, IB and MH made substantial contributions to the conception and design of the study. All authors were involved in acquisition of data. LK performed the statistical analyses. LPH drafted the first version of the manuscript with substantial contribution from LK. All authors contributed to the interpretation of data and revised the manuscript critically for important intellectual content. All authors gave final approval of the manuscript to be published.

Funding This study was funded by a grant from the German Ministry of Education and Research (01 GX 1031).

Competing interests All authors have completed the Unified Competing Interests form at http://www.icmje.org/coi_disclosure.pdf (available on request from the corresponding author). LPH reports personal fees from AstraZeneca for a roundtable discussion on clinical guidelines outside the submitted work CRK reports personal fees from Janssen Cilag and from Servier, outside the submitted work.

Ethics approval The trial was approved by the Institutional Review Board of the University Medical Center Freiburg (number 375/10) and the regional review boards responsible for local GPs (Ärztekammer Nordrhein, number 2012400; Sächsische Landesärztekammer, number EK-BR-74/12; Landesärztekammer Baden-Württemberg, number F-2012-065, and Ärztekammer Hamburg, number MC307/12)

Provenance and peer review Not commissioned; externally peer reviewed.

Data sharing statement No additional data are available.

Open Access This is an Open Access article distributed in accordance with the Creative Commons Attribution Non Commercial (CC BY-NC 4.0) license, which permits others to distribute, remix, adapt, build upon this work noncommercially, and license their derivative works on different terms, provided the original work is properly cited and the use is non-commercial. See: http:// creativecommons.org/licenses/by-nc/4.0/

\section{REFERENCES}

1. Statistisches Bundesamt, Fachserie 1, Reihe 2.2. Bevölkerung und Erwerbstätigkeit: Bevölkerung mit Migrationshintergrund-Ergebnisse des Mikrozensus 2014. Wiesbaden, 2015 (cited 2016 Aug 1). https:// www.destatis.de/DE/Publikationen/Thematisch/Bevoelkerung/
MigrationIntegration/Migrationshintergrund2010220147004.pdf? blob=publicationFile

2. Sheikh A, Gatrad R, Dhami S. Consultations for people from minority groups. BMJ 2008:337:a273.

3. Wagner EH. Meeting the needs of chronically ill people. $B M$ 2001;323:945-6.

4. Sheikh A. Ethnic minorities and their perceptions of the quality of primary care. BMJ 2009;339:b3797.

5. Worth A, Irshad T, Bhopal R, et al. Vulnerability and access to care for South Asian Sikh and Muslim patients with life limiting illness in Scotland: prospective longitudinal qualitative study. BMJ 2009;338: b183.

6. Griffiths C, Kaur G, Gantley M, et al. Influences on hospital admission for asthma in south Asian and white adults: qualitative interview study. BMJ 2001;323:962-6.

7. Rommel A, Saß AC, Born S, et al. [Health status of people with a migrant background and impact of socio-economic factors: first results of the German Health Interview and Examination Survey for Adults (DEGS1)]. Bundesgesundheitsblatt Gesundheitsforschung Gesundheitsschutz 2015;58:543-52. German.

8. Coulter A, Ellins J. Effectiveness of strategies for informing, educating, and involving patients. BMJ 2007;335:24-7.

9. Bodenheimer $\mathrm{T}$, Lorig $\mathrm{K}$, Holman $\mathrm{H}$, et al. Patient self-management of chronic disease in primary care. JAMA 2002;288:2469-75.

10. Engers $A$, Jellema $P$, Wensing $M$, et al. Individual patient education for low back pain. Cochrane Database Syst Rev 2008;(1): CD004057.

11. World Health Organisation. Health of migrants: the way forward. Report of a global consultation, Madrid, Spain, 3-5 March 2010. Geneva: WHO Press, 2010 [cited 2016 Mar 2]. http://www.who.int/ hac/events/consultation_report_health_migrants_colour_web.pdf? ua $=1$

12. Ingleby D. Good practice in health service provision for migrants. Migration and health in the European Union. Berkshire: Open University Press, 2011.

13. Benish SG, Quintana S, Wampold BE. Culturally adapted psychotherapy and the legitimacy of myth: a direct-comparison meta-analysis. J Couns Psychol 2011;58:279-89.

14. Bailey EJ, Cates CJ, Kruske SG, et al. Culture-specific programs for children and adults from minority groups who have asthma. Cochrane Database Syst Rev 2009;(1):CD006580.

15. Hawthorne K, Robles Y, Cannings-John R, et al. Culturally appropriate health education for type 2 diabetes mellitus in ethnic minority groups. Cochrane Database Syst Rev 2014;9: CD006424

16. Orleans CT, Boyd NR, Bingler R, et al. A self-help intervention for African-American smokers: tailoring cancer information service counseling for a special population. Prev Med 1998:27:S61-70.

17. Hölzel LP, Ries Z, Zill JM, et al. Development and testing of culturally sensitive patient information material for Turkish, Polish, Russian and Italian migrants with depression or chronic low back pain (KULTINFO): study protocol for a double-blind randomized controlled trial. Trials 2014;15:265.

18. Schenk L, Bau A-M, Borde T, et al. [A basic set of indicators for mapping migrant status. Recommendations for epidemiological practice]. Bundesgesundheitsb/ 2006:49:853-60. German.

19. Bundesärztekammer (BÄK), Kassenärztliche Bundesvereinigung (KBV), Arbeitsgemeinschaft der Wissenschaftlichen Medizinischen Fachgesellschaften (AWMF). Nationale VersorgungsLeitlinie Kreuzschmerz-Langfassung, 1. Auflage, Version 5. zuletzt verändert: Oktober 2015. 2010 [cited 2 Mar 2016]. http://www. versorgungsleitlinien.de/themen/kreuzschmerz

20. DGPPN, BÄK, KBV, et al., eds. S3-Leitlinie/Nationale VersorgungsLeitlinie Unipolare Depression-Langfassung. 2009 [cited 2 Mar 2016]. http://www.depression.versorgungsleitlinien.de

21. Su CT, Parham LD. Generating a valid questionnaire translation for cross-cultural use. Am J Occup Ther 2002:56:581-4.

22. Edwards $\mathrm{P}, \mathrm{Roberts} \mathrm{I}$, Clarke $\mathrm{M}$, et al. Methods to increase response rates to postal questionnaires. Cochrane Database Syst Rev 2007; (2):MR000008.

23. Stephenson M. Development and validation of the Stephenson Multigroup Acculturation Scale (SMAS). Psychol Assess 2000;12:77-88.

24. Garner M, Ning Z, Francis J. A framework for the evaluation of patient information leaflets. Health Expect 2012;15:283-94.

25. Hölzel LP, Ries Z, Dirmaier J, et al. Usefulness scale for patient information material (USE)—development and psychometric properties. BMC Med Inform Decis Mak 2015;15:34.

26. Löwe B, Spitzer R, Zipfel S, et al. Gesundheitsfragebogen für Patienten (PHQ D). Komplettversion und Kurzform. 2. Auflage. Karlsruhe: Pfizer, 2002. 
27. Mannion AF, Elfering A, Staerkle R, et al. Outcome assessment in low back pain: how low can you go? Eur Spine J 2005;14:1014-26.

28. WHO Regional Office for Europe. Well-Being measures in primary health care: the Depcare Project. Report on a WHO Meeting. Stockholm, Sweden, 1998 [cited 11 Feb 2016]. http://www.euro.who. int/_data/assets/pdf_file/0016/130750/E60246.pdf

29. Kriston L. Dealing with clinical heterogeneity in meta-analysis. Assumptions, methods, interpretation. Int J Methods Psychiatr Res 2013;22:1-15.

30. van Buuren S. Multiple imputation of discrete and continuous data by fully conditional specification. Stat Methods Med Res 2007;16:219-42.
31. Peugh JL, Enders CK. Using the SPSS mixed procedure to fit cross-sectional and longitudinal multilevel models. Educ Psychol Meas 2005;65:717-41.

32. Nierkers V, Hartman MA, Nicolaou M, et al. Effectiveness of cultural adaptations of interventions aimed at smoking cessation, diet, and/or physical activity in ethnic minorities. A systematic review. PLOS ONE 2013;8:e73373.

33. Chowdhary N, Jotheeswaran AT, Nadkarni A, et al. The methods and outcomes of cultural adaptations of psychological treatments for depressive disorders: a systematic review. Psychol Med 2014;44:1131-46. 